\title{
Radio(chemo)therapy in elderly patients with esophageal cancer: a feasible treatment with an outcome consistent with younger patients
}

\section{Philippe Rochigneux ${ }^{1,2}{ }^{*}$, Michel Resbeut ${ }^{1}$, Frédérique Rousseau ${ }^{3}$, Erwan Bories ${ }^{4}$, Jean-Luc Raoul ${ }^{5}$, Flora Poizat ${ }^{6}$ and Laurence Moureau-Zabotto ${ }^{1}$}

${ }^{1}$ Department of Radiation Oncology, Institut Paoli Calmettes, Marseille, France

2 Department of Medical Oncology, Centre Hospitalier Universitaire Vaudois, Lausanne, Switzerland

${ }^{3}$ Department of Oncogeriatry, Institut Paoli Calmettes, Marseille, France

${ }^{4}$ Endoscopic Unit, Institut Paoli Calmettes, Marseille, France

${ }^{5}$ Department of Medical Oncology, Institut Paoli Calmettes, Marseille, France

${ }^{6}$ Department of Biopathology, Institut Paoli Calmettes, Marseille, France

\section{Edited by:}

Tim Greten, National Cancer Institute, USA

Reviewed by:

Rupert Langer, University of Bern, Switzerland

Oxana V. Rusher, National Cancer

Institute, USA

\section{*Correspondence:}

Philippe Rochigneux, Department of Medical Oncology, Centre Hospitalier Universitaire Vaudois, Rue du Bugnon 46, Lausanne 1011, Switzerland e-mail: philippe.rochigneux@chuv.ch
Background: Although the prevalence of esophageal cancer increases in elderly patients, its clinical history and outcome after treatment remain poorly described.

Methods: Between January 2001 and December 2011, 58 patients (pts) older than 75 years received 3D-conformal radiotherapy (mean dose $51 \mathrm{~Gy}$ ) in two French cancer centers. 47/58 (82\%) patients received concomitant chemotherapy (with CDDP and/or FU regimens) and 8 patients underwent surgery after primary radiochemotherapy (RCT).

Results: Median age was 77.9 years and the performance status (PS) was 0 or 1 in $89 \%$. Tumors were mainly adenocarcinoma of lower esophagus or gastroesophageal junction $(n=51,89 \%)$, T3T4 $(n=54,95 \%)$, and N1 $(n=44,77 \%)$. The mean follow-up was 21.9 months. In the overall population, the median progression-free survival was 9.6 months and median overall survival (OS) was 14.5 months. Using univariate analysis, OS was significantly associated with age $(p=0.048)$, PS $(p<0.001)$, and surgery $(p=0.035)$. $35(60.3 \%)$ and 18 patients (31\%) experienced grade $1-2$ or 3-4 toxicity, respectively (CTCAE v4.0).

Conclusion: Radiochemotherapy in elderly patients is a feasible treatment and its outcome is close to younger patient's outcome published in the literature. Surgical resection, after comprehensive geriatric assessment, should be recommended as the standard treatment for adenocarcinoma of lower esophagus or gastroesophageal junction in elderly patients with good PS and low co-morbidity profile, as it is in younger patients.

Keywords: esophageal neoplasm, elderly patients, radiotherapy, chemoradiotherapy, esophagectomy

\section{INTRODUCTION}

Esophageal cancer (OC) is the eighth most common cancer worldwide, with 481,000 new cases (3.8\% of the total) estimated in 2008 , and the sixth most common cause of death from cancer with 406,000 deaths $(5.4 \%$ of the total) (1). In most western countries, squamous cell carcinoma (SCC) incidence rates continue to decrease while incidence of adenocarcinoma is rocketing up (2). Furthermore, OC has a very poor survival (overall ratio of mortality to incidence of 0.88 ) (3). The incidence of OC in elderly patients has rapidly increased in the Western countries over the past 25 years, with a specific mortality increasing with age (4).

Recently, the field of OC management improved in several ways: (i) demonstration that the dose of $50 \mathrm{~Gy}$ seemed to be the better option (5), (ii) evidence from meta-analysis in favor of neoadjuvant chemotherapy or chemoradiotherapy (6), and (iii) the demonstration of the good efficacy - safety balance in favor of FOLFOX regimen (5-FU and Oxaliplatin) when compared with usual 5-FU-CDDP (Cisplatin) (7). Nevertheless, none of these trials presented sub-group data analysis focused on elderly patients. Furthermore, patients older than 75 years are often excluded from clinical trials $(8,9)$ and there is a lack in prospective studies in this specific population. That leads to the fact that little is known about the optimal treatment of this population.

A retrospective cohort study of 3500 patients (10) reported that older people are less referred to cancer specialist and thus, have less intensive treatment, which may partially explain the poor results of OC management among elderly patients. Particularly, a larger number of older patients eligible for esophageal resection are contra-indicated with regards to the aggressiveness of the surgery. For non-resectable OC, the strategy generally adopted is radiotherapy with or without concomitant chemotherapy. In elderly patients however, the dose of radiation and the protocols 
of chemotherapy is non-consensual (for example, Servagi-Vernat et al. used CDDP alone, and Anderson et al. used 5-FU and mitomycin $\mathrm{C}$ in association) $(11,12)$.

The aim of this retrospective multicentric study was to analyze the management and the outcome of 58 elderly patients treated by radiotherapy with or without concomitant chemotherapy and with or without surgery for an OC in two French centers, between January 2001 and December 2011.

\section{MATERIALS AND METHODS ELIGIBILITY CRITERIA}

Inclusion criteria were as follows: histologically proven SCC or adenocarcinoma of the esophagus or gastroesophageal junction, local or loco-regional disease at diagnosis, age $\geq 75$ years, treatment by radiotherapy (exclusive or not) between January 2001 and December 2011 in two French centers. No selection was made regarding performance status (PS), co-morbidity, or biological characteristics. Comorbidities were estimated using the Charlson score adjusted on age (13), which combines a score for 19 disease co-morbidity categories (from 1 to 6 based on the relative risk of 1 -year mortality) and the patient's age (one point per decade from 50 to 70 years old).

\section{TUMORAL STAGING AND EVALUATION OF THE RESPONSE}

All patients underwent an initial gastrointestinal fibroscopy and ultrasonography (OGUS) with biopsies and a thoraco-abdominal CT-scan. Tumors were staged using CT-scan and OGUS, according to the seventh edition of the Union for International Cancer Control and the American Joint Committee on Cancer (14). The toxicity was evaluated by a weekly clinical examination, and with a biological evaluation before every cycle of chemotherapy. All toxicities were recorded using the Common Terminology Criteria for Adverse Events v4.0 (CTCAE). The tumor response was evaluated by an OGUS and a CT-scan realized 1 and 2 months after the end of treatment, every 3 months during the first year, and then every 6 months.

\section{TREATMENTS}

Every treatment was debated during a tumor board including at least a surgeon, a radiation oncologist, a medical oncologist, and a radiologist. Because of the retrospective approach of this study, an onco-geriatric evaluation was not systematically realized.

Radiation therapy was delivered using 3D-conformal RT. Gross Tumor Volume (GTV) was determined with every useful information (clinical examination, CT-scan, and endoscopy) and included the primary tumor site and regional macroscopically involved lymph nodes. For patients eligible for a surgical resection, the Planning Target Volume (PTV) was defined by a proximal and distal margin of $5 \mathrm{~cm}$ and radial margin of $1 \mathrm{~cm}$ around the GTV. In case of stomach's extension, the upper third part of the stomach was added to the PTV. For patients non-eligible for surgery, a radiation boost was often delivered on the GTV plus $2 \mathrm{~cm}$ margin in longitudinal extension, and $1 \mathrm{~cm}$ margin in sagittal and axial extension.

Concomitant chemotherapy was performed whenever possible, as decided by the multidisciplinary consultation meeting. Systemic treatment regimen was adapted to patient's characteristics (PS, co-morbidity, and biological results) and was based on platinum derivatives and/or $5 \mathrm{FU}$. Surgery was performed in accordance with the tumor board decision, after a surgical and a pre-anesthesia evaluation, and after a neoadjuvant RCT of $45 \mathrm{~Gy}$ with fractions of $1.8 \mathrm{~Gy} /$ day, 5 days a week. The choice of transthoracic or transhiatal esophagectomy was dictated by the location of the tumor and the preference of the surgeon.

\section{STATISTICAL ANALYSIS}

Overall survival (OS) was calculated from the date of initial positive biopsy until the date of death or the date of last follow-up. Progression-Free Survival (PFS) was estimated from the date of endoscopy to the date of progression (loco-regional or metastatic) or the date of death or last follow-up. Loco-regional progressions were proven histologically, whereas metastatic progressions were diagnosed on CT-scan. OS and PFS curves were constructed using the Kaplan-Meier method (15). Prognostic factors for OS and PFS were obtained using the log-rank test and statistical significance was defined with a $p$-value $<0.05$. All prognostic factors with a $p<0.2$ were included for a multivariate analysis using a Cox regression. Surgical and non-surgical populations were compared using a Pearson's $\chi^{2}$ test. Analyses were performed with SPSS v16.0.

\section{RESULTS}

\section{PATIENT AND TUMOR CHARACTERISTICS}

Fifty-eight patients were enrolled in this study, from two French Cancer Centers: Institut Paoli Calmettes, Marseille $(n=33)$ and Centre de Radiothérapie St Louis, Toulon $(n=25)$. The patients $>75$ years represent $9 \%$ of the total of patients treated by RT for an OC in these centers. Characteristics of patients and tumors are described in Table 1. Median age was 77.8 years (range of 7587 years). Most of the patients had a good PS: PS $0(n=12,20 \%)$ or PS $1(n=40,69 \%)$. Concerning co-morbidity, 37 patients $(64 \%)$ had a Charlson score $<5$ and $21(36 \%)$ had a Charlson score $\geq 5$, with a median Charlson score of 4 (3-7).

Among all the 58 histologically proven carcinoma, 43 were adenocarcinoma (74\%). Tumors involved mostly the gastroesophageal junction (GOJ) $(n=31)$ and the lower third of the esophagus $(n=20)$. A large majority of the patients presented a locally advanced tumor T3N0-1 $(n=41)$ or T4 N0-1 $(n=5)$.

\section{TREATMENT CHARACTERISTICS}

The main characteristics of the delivered treatments are described in Table 2. All patients underwent radiotherapy, with a mean delivered dose of 50.9 Gy (27-72 Gy). The median and mean numbers of treatment days were respectively 43 and 46 days (22-117).

Forty-seven patients received concomitant chemotherapy: 20 had weekly Carboplatin (AUC2), 10 had Herskovic regimen (4 CDDP/5 FU chemotherapy courses with $5 \mathrm{FU} 1000 \mathrm{mg} / \mathrm{m}^{2}$ at days 1-5 and CDDP at $75 \mathrm{mg} / \mathrm{m}^{2}$ at day 1$), 7$ had weekly CDDP (40 or $60 \mathrm{mg} / \mathrm{m}^{2}$ ), 4 had 5 FU-Carboplatin (every 21 days: $5 \mathrm{FU}$ : $750 \mathrm{mg} / \mathrm{m}^{2}$ at days 1-5; Carboplatin AUC4), 3 had FOLFOX 4, 2 had capecitabine $\left(100 \mathrm{mg} / \mathrm{m} / \mathrm{m}^{2}\right)$, and 1 had exclusive $5-\mathrm{FU}$ (dose unknown).

Exclusive RT (without chemotherapy or surgery) was performed in 11 patients, because of age $(n=3)$, co-morbidity 
Table 1 | Patient and tumor characteristics.

\begin{tabular}{|c|c|c|}
\hline Variable & $n=58$ & $(\%)$ \\
\hline \multicolumn{3}{|l|}{ AGE } \\
\hline $75-80$ & 42 & $(72.4)$ \\
\hline $80-85$ & 13 & $(22.4$ \\
\hline$>85$ & 3 & $(5.2$ \\
\hline \multicolumn{3}{|l|}{ SEX } \\
\hline Male & 43 & $(74.1)$ \\
\hline Female & 15 & $(25.8$ \\
\hline \multicolumn{3}{|c|}{ WHO PERFORMANCE STATUS } \\
\hline 0 & 12 & (20.6) \\
\hline 1 & 40 & $(68.9$ \\
\hline 2 & 5 & $(8.6$ \\
\hline 3 & 1 & $(1.7)$ \\
\hline \multicolumn{3}{|c|}{ CHARLSON SCORE ADJUSTED ON AGE } \\
\hline 3 & 17 & $(29.3$ \\
\hline 4 & 20 & $(34.4)$ \\
\hline 5 & 13 & $(22.4$ \\
\hline 6 & 5 & $(8.6)$ \\
\hline 7 & 3 & $(5.2)$ \\
\hline \multicolumn{3}{|c|}{ LOCALIZATION ESOPHAGUS } \\
\hline Upper one-third & 2 & $(3.4)$ \\
\hline Middle one-third & 5 & $(8.6)$ \\
\hline Lower one-third & 20 & $(34.5)$ \\
\hline GOJ & 31 & $(53.4)$ \\
\hline \multicolumn{3}{|l|}{ STAGE } \\
\hline TXNX & 2 & $(3.4$ \\
\hline T1N1 & 1 & $(1.7)$ \\
\hline $\mathrm{T} 2 \mathrm{~N} 1$ & 1 & $(1.7)$ \\
\hline T3NO & 4 & $(6.9$ \\
\hline T3N1 & 37 & $(63.8)$ \\
\hline T3N2 & 1 & $(1.7)$ \\
\hline T3NX & 7 & $(12.1)$ \\
\hline T4NO & 1 & $(1.7)$ \\
\hline $\mathrm{T} 4 \mathrm{~N} 1$ & 4 & $(6.9)$ \\
\hline \multicolumn{3}{|l|}{ HISTOLOGICALTYPE } \\
\hline Adenocarcinoma & 43 & $(74.1)$ \\
\hline Squamous cell carcinoma & 14 & $(24.1)$ \\
\hline Undifferentiated & 1 & $(1.7)$ \\
\hline \multicolumn{3}{|c|}{ HISTOLOGICAL DIFFERENTIATION } \\
\hline Well & 14 & $(24.1)$ \\
\hline Moderately & 13 & $(22.4)$ \\
\hline Poorly & 7 & $(12.1)$ \\
\hline Unknown & 24 & $(41.4)$ \\
\hline
\end{tabular}

GOJ, gastroesopageal junction.

$(n=2)$, asthenia $(n=2)$, patient's refusal $(n=1)$, or unknown reasons $(n=3)$.

Eight patients underwent esophagectomy, including seven transhiatal surgeries and one transthoracic Lewis Santy procedure. All the operated patients had GOJ cancer, an age $<80$ years, a Charlson score $\leq 4$, and a good PS (PS 0-1: $n=7$; PS 2: $n=1$ ). Three patients had pathological lymph nodes on the post-operative findings (see Table S1 in Supplementary Material) but none of them was treated with an adjuvant chemotherapy.
Table 2 | Treatment characteristics

\begin{tabular}{lcc}
\hline Variable & \multicolumn{2}{c}{ Total } \\
\cline { 3 - 3 } & $\mathbf{N}^{\mathbf{0}}$ & (\%) \\
\hline RADIATION THERAPY $(\boldsymbol{N}=\mathbf{5 8})$ & & $(39.6)$ \\
Dose $<50.4 \mathrm{~Gy}$ & 23 & $(20.6)$ \\
Dose $=50.4 \mathrm{~Gy}$ & 12 & $(39.6)$ \\
Dose $>50.4 \mathrm{~Gy}$ & 23 & $( \pm 8.4)$ \\
Mean dose (Gy) & 50.9 & \\
CHEMORADIOTHERAPY PROTOCOL $(\boldsymbol{N}=\mathbf{4 7})$ & $(57.4)$ \\
Weekly CDDP or Carboplatin & 27 & $(36.2)$ \\
5-FU and platinum regimen & 17 & $(6.4)$ \\
5-FU alone & 3 & \\
\hline
\end{tabular}

CDDP, Cisplatine; 5-FU, 5 Fluoro-Uracile.

\section{TREATMENT OUTCOME AND SURVIVAL}

The mean follow-up of the population was 21.9 months (2.1-100.9).

The median PFS of the overall population was $9.6 \pm 3.9$ months (Figure 1A). Using univariate analysis, PS status and age $<78$ years (inferior to the median) were the only significant predictive factors for PFS ( $p=0.012$ and $p=0.019$, respectively). The following factors were not significantly associated with PFS: sex, Charlson score, surgery, concomitant chemotherapy, and RT dose (see Table 3). Thirty-four patients relapsed: 17 loco-regionally, 8 with distant metastases, and 9 with both loco-regional and distant relapse. The 2- and 3-year-cumulative rates of local recurrence were 36.2 and $41.4 \%$, respectively. The only positive predictive factor for local control was age: 2 -years local relapse for patients $<78$ years was $64.0 \%$, vs. $92.6 \%$ for patients $\geq 78$ years $(p=0.021)$. Concerning metastatic recurrence, no prognostic factors were identified and the preferential localizations were mainly pleuropulmonar $(n=5)$, peritoneal $(n=3)$, hepatic $(n=2)$, and cerebral $(n=1)$, with a few unknown data $(n=5)$.

The median overall survival (OS) of the overall population was $14.5 \pm 4.7$ months (standard deviation), and 2 and 3 years-overall survival rates were 25.9 and $15.5 \%$, respectively (Figure 1B). Using univariate analysis, the OS was positively influenced by age $<78$ years $(p=0.048$, Figure $S 1$ in Supplementary Material), a good PS ( $p<0.001$, Figure S2 in Supplementary Material), and the realization of surgery $(p=0.035)$. Details of the univariate analysis for OS are given in Table 3.

Curative esophagectomy (Figure 2) was associated with a median OS of $18.3 \pm 9.7$ vs. $10.5 \pm 3.5$ months for patient without surgery $(p=0.035)$.

There was no significant difference in terms of OS in univariate analysis for sex, Charlson score, histology, degree of differentiation, and tumor size $>50 \mathrm{~mm}$, usTN, pTN, RT dose, and concomitant chemotherapy. Accordingly with the univariate analysis results, none of the prognostic factors were significative in multivariate analysis.

47/58 died within 2 years: $30 / 47$ deaths were due to OC disease progression, 6/47 due to complications of therapy, and the remainder to non-cancer (6/47) or unknown causes (5/47). 


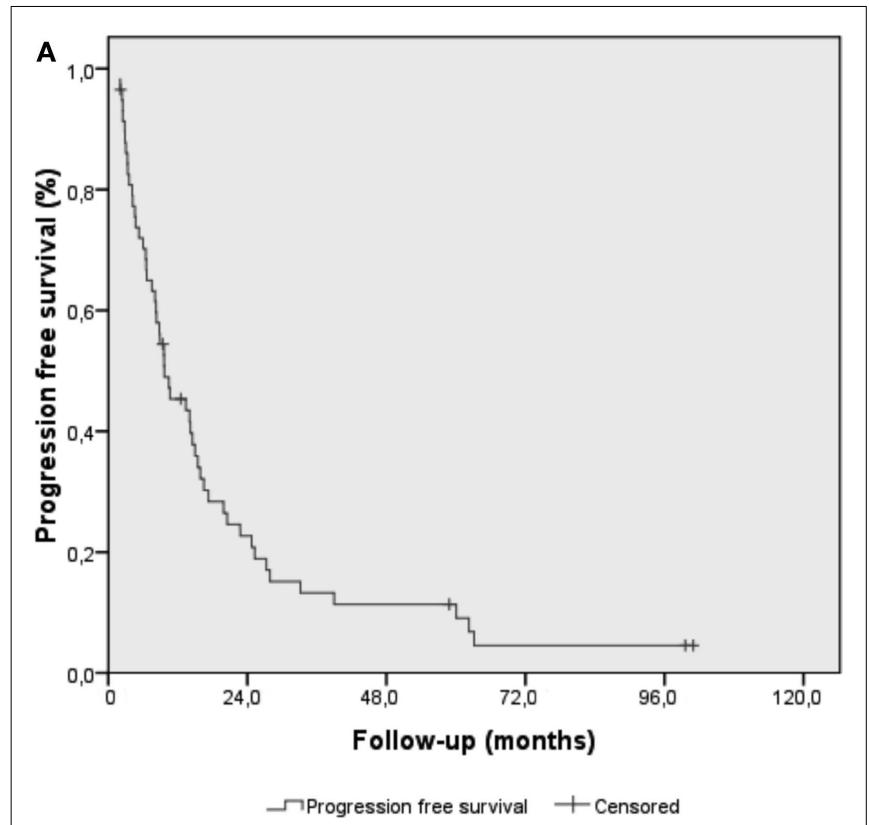

B

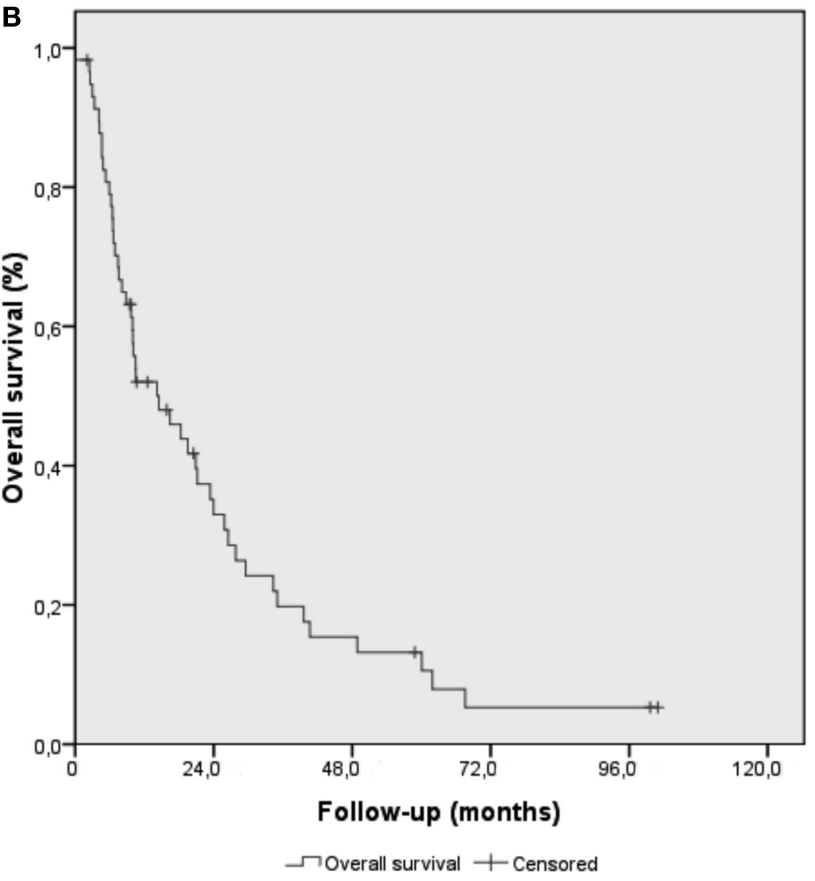

FIGURE 1 | Kaplan-Meier methods for elderly patients treated for esophageal and gastroesophageal cancer. (A) Progression-free survival curve (B) overall survival curve.

\section{TOLERANCE}

During RT or RCT, grade 1-2 and 3-4 side effects occurred in 35 patients $(60.3 \%)$ and in 18 patients $(31 \%)$, respectively. The main hematologic side effects were febrile neutropenia ( $n=7,14.9 \%)$, thrombopenia (grade 3-4: $n=6,12.8 \%$ ), and anemia (grade 3-4: $n=3,6.4 \%)$. The main non-hematologic side effects were dysphagia (grade 3-4, $n=9,19.1 \%$ ), nausea (grade 3-4: $n=3,6.4 \%$ ), and asthenia (grade $1-2: n=6,12.7 \%$ and grade $3-4: n=1$ ). There were only a few grade $1-2$ mucositis and skin toxicity $(n=4$ and $n=1$, respectively). Interruptions of radiation therapy occurred in 13 patients $(22 \%)$, temporarily $(n=7)$ or definitively $(n=6)$ at a mean dose of $35.8 \mathrm{~Gy}(26-40 \mathrm{~Gy})$.

During RCT $(n=47), 18$ patients $(38.2 \%)$ had to be hospitalized, mainly for severe malnutrition $(n=7)$ or febrile neutropenia $(n=7)$. One toxic death occurred during RCT (asthenia, dysphagia).

Patients with exclusive RT $(n=11)$ had no hematologic side effects but more grade $3-4$ asthenia $(n=5)$ and a comparable dysphagia (grade $3-4, n=2,18.2 \%$ ) and hospitalization rate $(n=3,27.3 \%)$. One toxic death occurred during exclusive RT (asthenia, severe malnutrition).

Surgical complications were described as follows: one gastric necrosis after gastroplasty, one anastomotic fistula with subcutaneous emphysema (both of them recovered after transfer in an intensive care unit), one anastomotic stenosis ( 2 months after the transthoracic procedure, treated by endoscopic dilatations), and one recurrent paralysis (with a good rehabilitation). None of the eight patients operated died in the 30 days after surgery.

\section{DISCUSSION}

We present here a large cohort of elderly patients treated with radiotherapy for an esophageal cancer.

Due to its retrospective nature, our analysis suffers from limitations, including the absence of a consistent onco-geriatric evaluation and systematic integration of quality-of-life assessment. Furthermore, a median follow-up of 21.9 months is rather short to precisely evaluate overall and/or specific survival, as well as their prognostic factors. This might explain why some validated prognostic factors do not reach significance in our results (e.g., T stage). In addition, therapeutic strategies were rather heterogeneous, in part due to the improvements made over the 10 years inclusion period. Finally, one could argue that SCC and adenocarcinoma are different diseases, even though most analysis including ours did not show any major differences in outcome.

On the other hand, this study concerned a consistent number of patients treated in only two experimented cancer centers, avoiding misleading factors such as variations of clinical staging between physicians. Technical reproducibility was guaranteed by the fact that the same team performed the endoscopic evaluation in the two centers.

In comparison with published data, our population is more homogeneous regarding age, as we chose an inferior limit at 75 years instead of 70 years (11) or 65 years (12). Furthermore, patients were not selected for PS or co-morbidity, contrary to the study of Anderson et al. in which only patients with Karnofsky Index $>70 \%$ were included and in the study of ServagiVernat et al. in which $50 \%$ of patients were excluded for PS $>2$ or Charlson score $>4$. Consequently, our population can be considered as representative of routine clinical practice. Finally, every patient's case was discussed in a multidisciplinary meeting with a medical oncologist, a radiation oncologist, and a surgeon. All the range of treatments, even surgery, could be discussed, which prevent the risk of undertreatment that is huge in elderly patients. 
Table 3 | Univariate analysis for overall and progression-free survival in population treated in a curative intent.

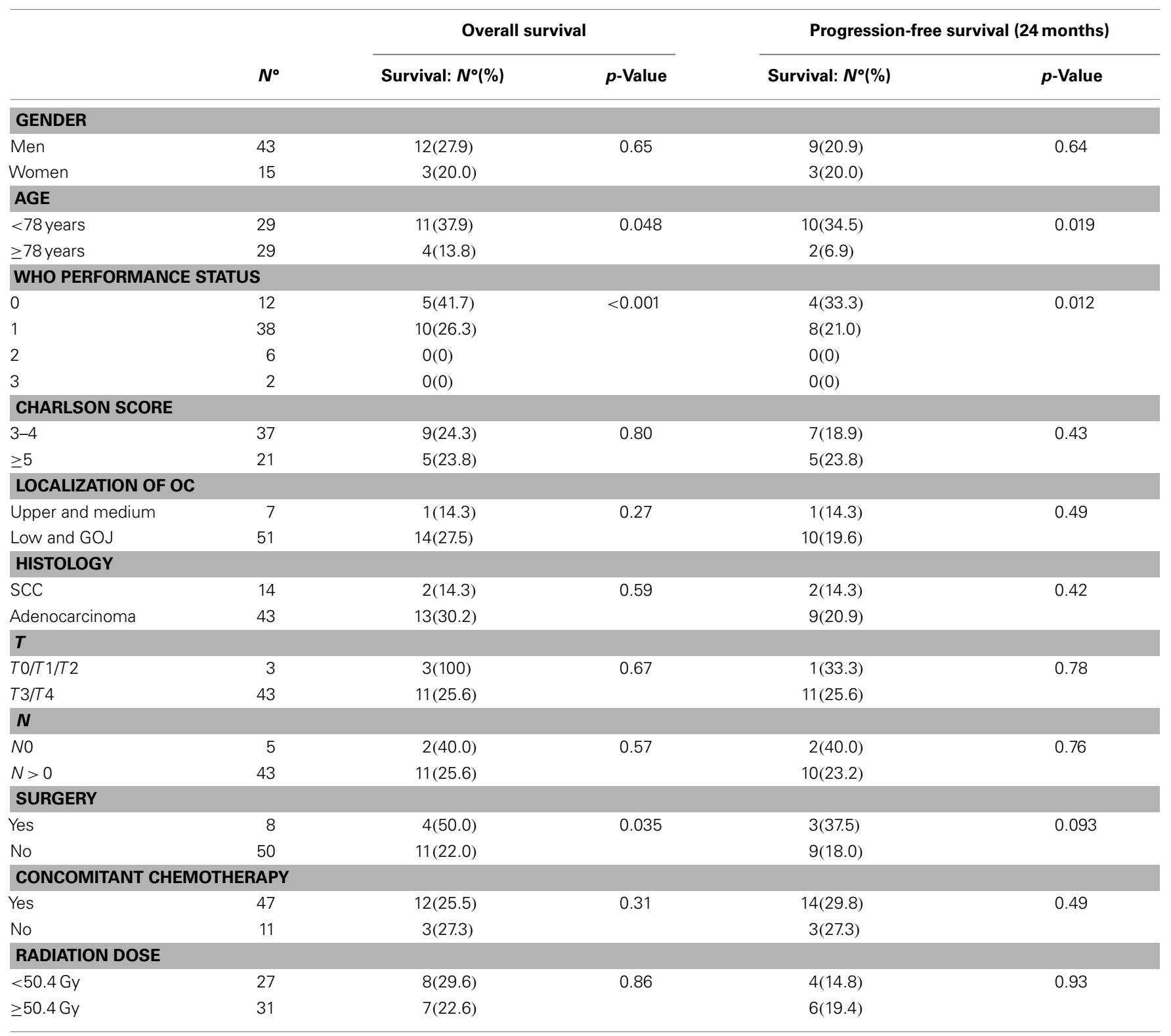

OC, esophageal cancer; GOJ, gastroesophageal junction; SCC, squamous cell carcinoma.

The results we found in terms of OS and PFS are consistent with those published in the literature, notably in the largest cohort of 109 elderly patients treated with exclusive RCT with a median OS and PFS of 15.2 and 8.3 months, respectively (16). In another small prospective study of 22 patients $>75$ years old treated by exclusive RCT (50 Gy and weekly cisplatin), the median OS was 15 months (11). Only a study by a team from Memorial Sloan Kettering described a better OS (median of 35 months) but with only 22 patients included, who were younger and with fewer comorbidities compared to our study (12).

Moreover, patient outcomes described here are not so far from the results published in the literature for younger counterparts. In the most important clinical trials, including patients below the age of 75 years old, median OS ranged between 13.0 and 19.3 months
$(5,8,17)$. This emphasizes the fact that curative treatments of OC should not be rejected only on age's argument.

In our study, the best results in terms of OS were obtained for patients who underwent neoadjuvant RCT followed by esophagectomy. Coia et al. also found a superiority of esophagectomy in the 2 years survival rate $(50.2$ vs. $31.2 \%)$ in the general population receiving RT in MSKCC between 1992 and 1994 (18). In a study by Ruol and colleagues, concerning 62 patients over 80 years old, esophagectomy was found to be a prognostic factor in OC with an important difference in OS: 14.6 vs. 5.1 months in resected and non-resected patients, respectively (19). Despite the fact that esophagectomy is a major surgical procedure, Markar et al. indicated that there were no significant differences in terms of length of hospitalization and survival rate for patients over 80 years in 


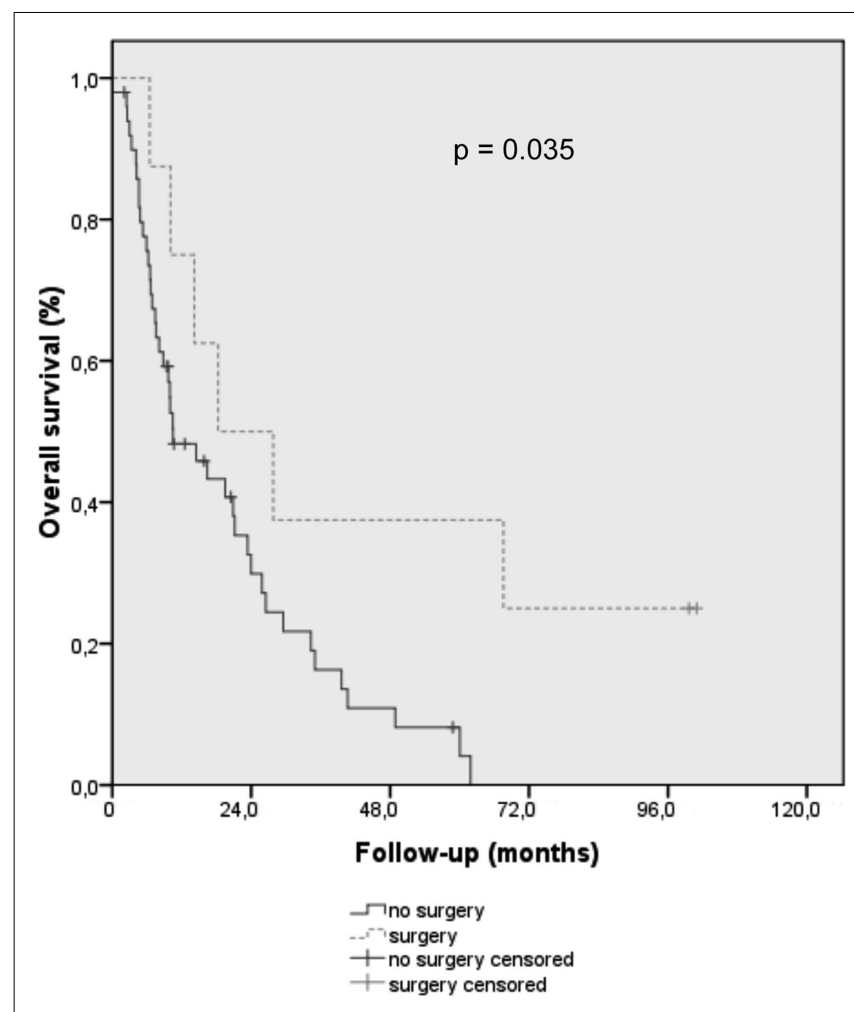

FIGURE 2 | Overall survival curve using Kaplan-Meier methods for elderly patients treated for esophageal and gastroesophageal cancer, with surgery (dotted line) or without (full line).

comparison to younger counterparts (20). In our study, surgery was associated with local complications (anastomosis stenosis, necrosis of gastroplasty, and fistula) but without perioperative death. Along this line, previous results showed that a lower 30day mortality rate after esophagectomy is obtained when surgery is realized in a specialized center (21). Together with previous evidence (22), our results suggest that surgical resection is feasible even in elderly patients, which was not predictable, because age still appears as a risk factor in certain predictive scores (23).

Concerning RCT tolerance, our results are close to the data of the literature as Tougeron and Anderson presented 22 and $36 \%$ of grade 3-4 toxicity, respectively. In elderly patients with $5 \mathrm{FU}$ or platinum regimen, febrile neutropenia is a major issue that must be carefully managed, notably relying on GCSF (24) or eventually with an antibiotic prophylaxis. Another challenge is to keep a calories intake around $1500 \mathrm{kcal}$, as far as possible using nutritional supplements or enteral nutrition with gastrostomy or jejunostomy (25). Onco-geriatric systematic evaluation is another clue to decrease toxicity by managing age-related fragility (26-28). We can also hypothesize that toxicity of RT will decline in the next few years thanks to the technical progress of RT as gating technique and new treatment planning techniques as intensity-modulated radiotherapy including volumetric modulated arc therapy (29-31).

In conclusion, our results suggest that a curative treatment of OC based on RT is feasible on patient over 75 years, with an acceptable tolerance. The outcome remains poor but consistent with results in younger patients. With the use of a comprehensive geriatric assessment, no treatment modification is needed whatever the age of patients. Surgical resection should be recommended as the standard treatment for adenocarcinoma of lower esophagus or gastroesophageal junction in elderly patients with good PS and low co-morbidity profile, as it is in younger patients.

\section{ACKNOWLEDGMENTS}

This study, undertaken by Institut Paoli Calmettes, Marseille, France, received no financial support. This study was presented in the Monoco Age Oncology, Monaco, France, March 2013. We thank all Radiation Oncology staff for their support and cooperation, and Jeremy Oriol for revising English language.

\section{SUPPLEMENTARY MATERIAL}

The Supplementary Material for this article can be found online at http://www.frontiersin.org/journal/10.3389/fonc.2014. 00100/abstract

Figure S1 | Overall survival curve using Kaplan-Meier methods for elderly patients treated for esophageal and gastroesophageal cancer, with age $<78$ years (blue line) or $>78$ years (green line).

Figure S2 | Overall survival curve using Kaplan Meier methods for elderly patients treated for esophageal and gastroesophageal cancer according performance status (PS)

\section{Table S1 | Pathological findings after oesophagectomy}

\section{REFERENCES}

1. Bray F, Ren J-S, Masuyer E, Ferlay J. Global estimates of cancer prevalence for 27 sites in the adult population in 2008. Int J Cancer (2013) 132(5):1133-45. doi:10.1002/ijc.27711

2. Jemal A, Center MM, DeSantis C, Ward EM. Global patterns of cancer incidence and mortality rates and trends. Cancer Epidemiol Biomarkers Prev (2010) 19(8):1893-907. doi:10.1158/1055-9965.EPI-10-0437

3. Ferlay J, Shin HR, Bray F, Forman D, Mathers C, Parkin DM. Estimates of worldwide burden of cancer in 2008: GLOBOCAN 2008. Int J Cancer (2010) 127(12):2893-917. doi:10.1002/ijc.25516

4. Pera M, Manterola C, Vidal O, Grande L. Epidemiology of esophageal adenocarcinoma. J Surg Oncol (2005) 92(3):151-9. doi:10.1002/jso.20357

5. Minsky BD, Pajak TF, Ginsberg RJ, Pisansky TM, Martenson J, Komaki R, et al. INT 0123 (Radiation Therapy Oncology Group 94-05) phase III trial of combined-modality therapy for esophageal cancer: high-dose versus standarddose radiation therapy. J Clin Oncol (2002) 20(5):1167-74. doi:10.1200/JCO.20. 5.1167

6. Gebski V, Burmeister B, Smithers BM, Foo K, Zalcberg J, Simes J, et al. Survival benefits from neoadjuvant chemoradiotherapy or chemotherapy in oesophageal carcinoma: a meta-analysis. Lancet Oncol (2007) 8(3):226-34. doi:10.1016/S1470-2045(07)70039-6

7. Conroy T, Yataghène Y, Etienne PL, Michel P, Senellart H, Raoul JL, et al. Phase II randomised trial of chemoradiotherapy with FOLFOX4 or cisplatin plus fluorouracil in oesophageal cancer. Br J Cancer (2010) 103(9):1349-55. doi:10.1038/sj.bjc.6605943

8. Stahl M, Walz MK, Stuschke M, Lehmann N, Meyer HJ, Riera-Knorrenschild J, et al. Phase III comparison of preoperative chemotherapy compared with chemoradiotherapy in patients with locally advanced adenocarcinoma of the esophagogastric junction. J Clin Oncol (2009) 27(6):851-6. doi:10.1200/JCO. 2008.17.0506

9. van Hagen P, Hulshof MC, van Lanschot JJ, Steyerberg EW, van Berge Henegouwen MI, Wijnhoven BP, et al. Preoperative chemoradiotherapy for esophageal or junctional cancer. N Engl J Med (2012) 366(22):2074-84. doi:10.1056/NEJMoa1112088 
10. Steyerberg EW, Neville B, Weeks JC, Earle CC. Referral patterns, treatment choices, and outcomes in locoregional esophageal cancer: a population-based analysis of elderly patients. J Clin Oncol (2007) 25(17):2389-96. doi:10.1200/ JCO.2006.09.7931

11. Servagi-Vernat S, Bosset M, Crehange G, Buffet-Miny J, Puyraveau M, Maingon P, et al. Feasibility of chemoradiotherapy for oesophageal cancer in elderly patients aged $\geq 75$ years. Drugs Aging (2009) 26(3):255-62. doi:10.2165/ 00002512-200926030-00006

12. Anderson SE, Minsky BD, Bains M, Hummer A, Kelsen D, Ilson DH. Combined modality chemoradiation in elderly oesophageal cancer patients. Br J Cancer (2007) 96(12):1823-7. doi:10.1038/sj.bjc.6603821

13. Charlson M, Szatrowski TP, Peterson J, Gold J. Validation of a combined comorbidity index. J Clin Epidemiol (1994) 47(11):1245-51. doi:10.1016/08954356(94)90129-5

14. Rusch VW, Rice TW, Crowley J, Blackstone EH, Rami-Porta R, Goldstraw P. The seventh edition of the American Joint Committee on Cancer/International Union against Cancer Staging Manuals: the new era of data-driven revisions. J Thorac Cardiovasc Surg (2010) 139(4):819-21. doi:10.1016/j.jtcvs.2010. 02.013

15. Kaplan EL, Meier P. Nonparametric estimation from incomplete observations. J Am Stat Assoc (1958) 53(282):457. doi:10.1080/01621459.1958.10501452

16. Tougeron D, Di Fiore F, Thureau S, Berbera N, Iwanicki-Caron I, Hamidou H, et al. Safety and outcome of definitive chemoradiotherapy in elderly patients with oesophageal cancer. Br J Cancer (2008) 99(10):1586-92. doi:10.1038/sj.bjc. 6604749

17. Bedenne L, Michel P, Bouché O, Milan C, Mariette C, Conroy T, et al. Chemoradiation followed by surgery compared with chemoradiation alone in squamous cancer of the esophagus: FFCD 9102. J Clin Oncol (2007) 25(10):1160-8. doi:10.1200/JCO.2005.04.7118

18. Coia LR, Minsky BD, Berkey BA, John MJ, Haller D, Landry J, et al. Outcome of patients receiving radiation for cancer of the esophagus: results of the 1992-1994 patterns of care study. J Clin Oncol (2000) 18(3):455-62.

19. Ruol A, Portale G, Castoro C, Merigliano S, Cavallin F, Battaglia G, et al. Management of esophageal cancer in patients aged over 80 years. Eur J Cardiothorac Surg (2007) 32(3):445-8. doi:10.1016/j.ejcts.2007.06.014

20. Markar SR, Low DE. Physiology, not chronology, dictates outcomes after esophagectomy for esophageal cancer: outcomes in patients 80 years and older. Ann Surg Oncol (2013) 20(3):1020-6. doi:10.1245/s10434-012-2703-x

21. Dikken JL, van Sandick JW, Allum WH, Johansson J, Jensen LS, Putter H, et al. Differences in outcomes of oesophageal and gastric cancer surgery across Europe. Br J Surg (2013) 100(1):83-94. doi:10.1002/bjs.8966

22. Camerlo A, D'Journo XB, Ouattara M, Trousse D, Doddoli C, Thomas PA. Adenocarcinoma of the esophagus and esophagogastric junction in patients older than 70 years: results of neoadjuvant radiochemotherapy followed by transthoracic esophagectomy. J Visc Surg (2012) 149(3):e203-10. doi:10.1016/j.jviscsurg. 2012.03.006

23. Steyerberg EW, Neville BA, Koppert LB, Lemmens VE, Tilanus HW, Coebergh JW, et al. Surgical mortality in patients with esophageal cancer: development and validation of a simple risk score. J Clin Oncol (2006) 24(26):4277-84. doi:10.1200/JCO.2005.05.0658
24. Smith TJ, Khatcheressian J, Lyman GH, Ozer H, Armitage JO, Balducci L et al. 2006 update of ASCO practice guideline recommendations for the use of white blood cell growth factors: guideline summary. J Oncol Pract (2006) 2(4):196-201. doi:10.1200/JOP.2.4.196

25. Clavier J-B, Antoni D, Atlani D, Ben Abdelghani M, Schumacher C, Dufour $\mathrm{P}$, et al. Baseline nutritional status is prognostic factor after definitive radiochemotherapy for esophageal cancer. Dis Esophagus (2012). doi:10.1111/j. 1442-2050.2012.01441.x

26. Balducci L, Extermann M. Management of cancer in the older person: a practical approach. Oncologist (2000) 5(3):224-37. doi:10.1634/theoncologist.5-3-224

27. Balducci L. Management of cancer in the elderly. Oncology (Williston Park) (2006) 20(2):135-143; discussion 144, 146, 151-152.

28. Terret C, Zulian GB, Naiem A, Albrand G. Multidisciplinary approach to the geriatric oncology patient. J Clin Oncol (2007) 25(14):1876-81. doi:10.1200/ JCO.2006.10.3291

29. Yaremko BP, Palma DA, Erickson AL, Pierce G, Malthaner RA, Inculet RI, et al. Adjuvant concurrent chemoradiation using intensity-modulated radiotherapy and simultaneous integrated boost for resected high-risk adenocarcinoma of the distal esophagus and gastro-esophageal junction. Radiat Oncol (2013) 8(1):33. doi:10.1186/1748-717X-8-33

30. Kole TP, Aghayere O, Kwah J, Yorke ED, Goodman KA. Comparison of heart and coronary artery doses associated with intensity-modulated radiotherapy versus three-dimensional conformal radiotherapy for distal esophageal cancer. Int J Radiat Oncol Biol Phys (2012) 83(5):1580-6. doi:10.1016/j.ijrobp. 2011.10 .053

31. Fakhrian K, Oechsner M, Kampfer S, Schuster T, Molls M, Geinitz H. Advanced techniques in neoadjuvant radiotherapy allow dose escalation without increased dose to the organs at risk: planning study in esophageal carcinoma. Strahlenther Onkol (2013) 189(4):293-300. doi:10.1007/s00066-012-0297-7

Conflict of Interest Statement: The authors declare that the research was conducted in the absence of any commercial or financial relationships that could be construed as a potential conflict of interest.

Received: 23 March 2014; paper pending published: 13 April 2014; accepted: 23 April 2014; published online: 12 May 2014.

Citation: Rochigneux P, Resbeut M, Rousseau F, Bories E, Raoul J-L, Poizat F and Moureau-Zabotto L (2014) Radio(chemo)therapy in elderly patients with esophageal cancer: a feasible treatment with an outcome consistent with younger patients. Front. Oncol. 4:100. doi: 10.3389/fonc.2014.00100

This article was submitted to Gastrointestinal Cancers, a section of the journal Frontiers in Oncology.

Copyright (C) 2014 Rochigneux, Resbeut, Rousseau, Bories, Raoul, Poizat and Moureau-Zabotto. This is an open-access article distributed under the terms of the Creative Commons Attribution License (CC BY). The use, distribution or reproduction in other forums is permitted, provided the original author(s) or licensor are credited and that the original publication in this journal is cited, in accordance with accepted academic practice. No use, distribution or reproduction is permitted which does not comply with these terms. 